Landslides (2015) 12:631-640 DOI 10.1007/s10346-015-0586-1 Received: 29 April 2015 Accepted: 6 May 2015 Published online: 12 June 2015 (c) Springer-Verlag Berlin Heidelberg 2015
Kyoji Sassa

\section{ISDR-ICL Sendai Partnerships 2015-2025 for global promotion of understanding and reducing landslide disaster risk}

\section{Introduction}

This article reviews the process and the background of the Sendai Partnerships 2015-2025 proposed by the International Consortium on Landslides, from its foundation to 2005 Letter of Intent proposed in the Second United Nations World Conference on Disaster Reduction (WCDR) in Kobe, Japan, in 2005, and the 2006 Tokyo Action Plan as the first stage of development to the Sendai Partnerships. It further reviews the 1oth Anniversary Conference of International Consortium on Landslides (ICL) that was held in January 2012 where the ICL Strategic Plan 2012-2021 was developed. Following the Strategic Plan, ICL-IPL Conference was organized in Kyoto, Japan, in November 2013 when the concept and the initial draft of the ICL-IPL Sendai Partnerships to be linked to Third United Nations World Conference on Disaster Risk Reduction (WCDRR) were adopted. A process to establish the Sendai Partnerships in the Third WCDRR was examined in the International Forum "Urbanization and Landslide Disaster" held in Kyoto University, in October 2014. Thereafter, consultations over and the revision of the proposed partnerships were carried out to reach the final version of the Sendai Partnerships. The final version was approved in a formal "Working Session" of the Third WCDR $\mathrm{R}$, agreed, and signed by the 16 intergovernmental, international, and national organizations. Those processes and the signing ceremony as well as the Sendai Partnerships are reported in this article. ICL invites all relevant organizations and individuals to support this voluntary contribution to the Third WCDRR, Sendai, Japan.

The initial stage from ICL foundation in 2002 to the 2006 Tokyo Action Plan

The ICL was founded on 21 January 2002 with support from United Nations Educational, Scientific, and Cultural Organization (UNESCO), World Meteorological Organization (WMO), Food and Agriculture Organization of the United Nations (FAO), United Nations International Strategy for Disaster Risk Reduction (UNISDR), International Union of Geological Sciences (IUGS) and with participation of two Japanese Ministries (Ministry of Education, Culture, Sports, Science and Technology and the Ministry of Foreign Affairs) to promote landslide research for the benefit of society and the environment and capacity building, including education, notably in developing countries (Sassa 2004a). ICL has established the International Programme on Landslides (IPL) as an international initiative of ICL in 2002 (Sassa 2004b). IPL aims to conduct international cooperative research and capacity building.

ICL proposed a thematic session on landslides to take place at the Second United Nations World Congress on
Disaster Reduction (WCDR), Kobe, Japan, in 2005. ICL was advised to broaden the scope of that session to combine it with a thematic session on floods. Then, both groups jointly organized the thematic session $3.8 \mathrm{New}$ International Initiative for Research and Risk Mitigation of Floods (IFI) and Landslides (IPL) at the Second WCDR, Kobe, Japan, in 2005. ICL proposed the Letter of Intent aiming to provide a platform for a holistic approach in research and learning on "Integrated Earth System Risk Analysis and Sustainable Disaster Management" in this session. It was adopted in the session and agreed with signature from seven global stakeholders (UNESCO, WMO, FAO, UNISDR, United Nations University (UNU), International Council for Science (ICSU), World Federation of Engineering Organizations (WFEO)) within 2005.

Based on this Letter of Intent, the 2006 Tokyo Action Plan-strengthening research and learning on landslide and related earth system disasters for global risk preparedness-was adopted by participants in the 2006 Tokyo Round Table Discussion "Strengthening Research and Learning on Earth System Risk Analysis and Sustainable Disaster Management within UN-ISDR as Regards to Landslides-towards a dynamic global network of the International Programme on Landslides (IPL), which was held at the United Nations University, Tokyo from 18 to 20 January 2006 (Sassa 2006). The Tokyo Action Plan proposed the World Landslide Forum (WLF) held every 3 years, the identification of World Centres of Excellence on Landslide Risk Reduction (WCoE) acting for 3 years at each World Landslide Forum, and the establishment of the IPL Global Promotion Committee (IPL-GPC) for the management of an upgraded IPL. IPL-GPC consists of all ICL member organizations and ICL supporting organizations exchanging MOU with ICL for the implementation of IPL or organizations providing financial supports to IPL. All signatory organizations of the Letter of Intent supported IPL, and each of UNESCO, WMO, FAO, UNISDR, UNU, ICSU, WFEO exchanged MOU for the implementation of IPL. This constitutes the current stage of IPL.

FAO, Food and Agriculture Organization of the United Nations; ICSU, International Council for Science; IPL, International Programme on Landslides; IUGS, International Union of Geological Sciences; MEXT, Ministry of Education, Culture, Sports, Science and Technology, Government of Japan; UNESCO, United Nations Educational, Scientific and Cultural Organization; UNISDR, United Nations International Strategy for Disaster Risk Reduction; UNU, United Nations University; WFEO, World Federation of Engineering Organizations; WMO, World Meteorological Organization

The second stage from the 10th Anniversary Conference in 2012 to the International Forum "Urbanization and Landslide Disaster" in 2014

ICL organized a 1oth Anniversary Conference on 17-20 January 2012 in Kyoto with financial supports from the 


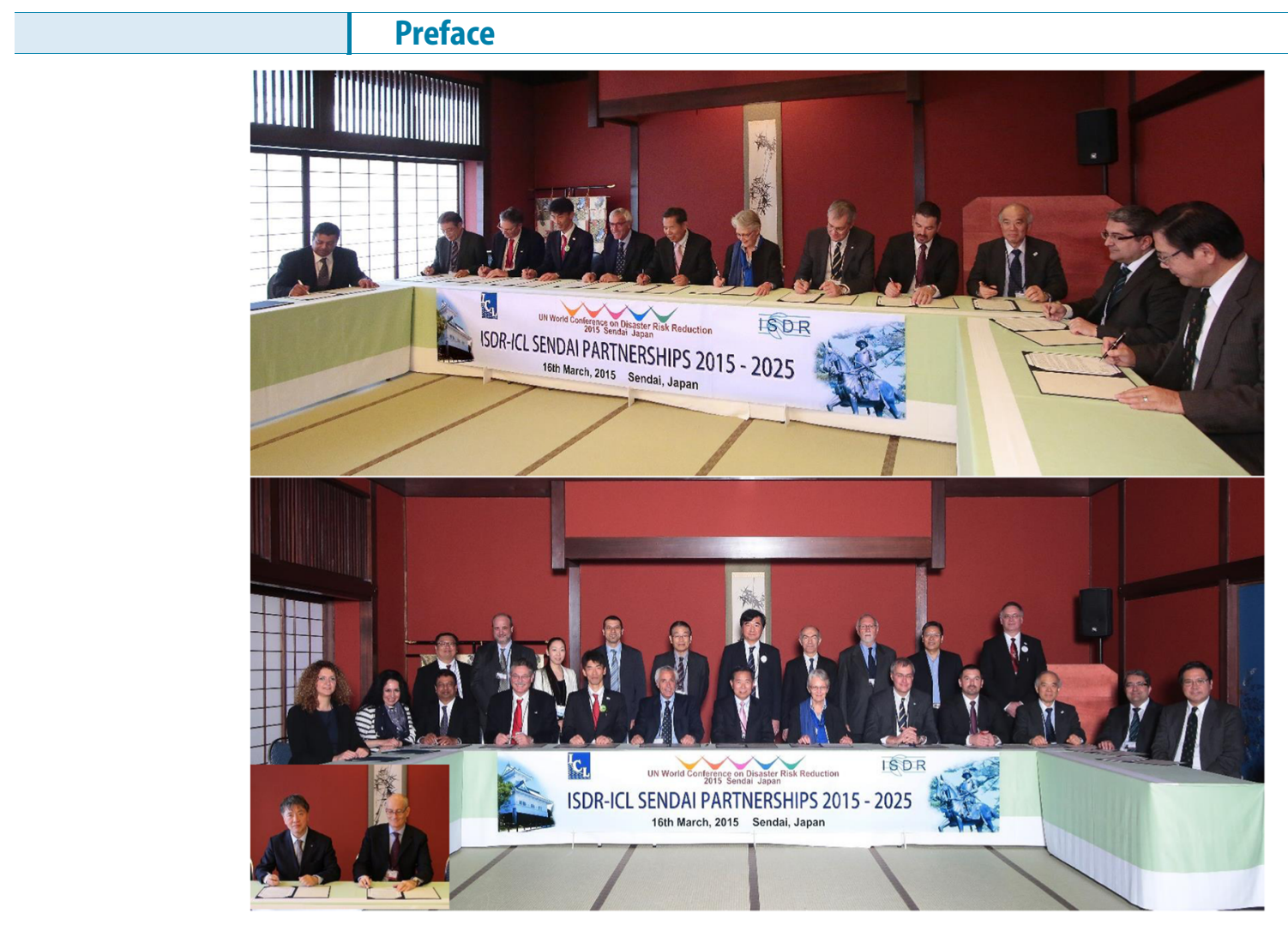

Fig. 1 Signing ceremony of ISDR-ICL Sendai Partnerships 2015-2025. Front (left to right) Sorrenti Ambra (for Franco Gabrielli, Italian Civil Protection), Irasema Alcantara-Ayala (for Gordon Mcbean, ICSU), Srikantha Herath (for Kazuhiko Takeuchi, UNU), Roland Oberhansli (IUGS), Kaoru Saito (Cabinet Office, Japan), Giuseppe Arduino (for Qunli Han, UNESCO), Kyoji Sassa (ICL), Margareta Wahlström (UNISDR), Dominique Burgeon (FAO), Robert Mikac (for Croatia Civil Protection), Takashi Onishi (Science Council of Japan), Alik Ismail-Zedeh (IUGG), Kaoru Takara (for Kayo Inaba, Kyoto University). Back (left to right) Hiroshi Fukuoka (ICL), Nicola Casagli (ICL), Yuki Matsuoka (UNISDR), Alexandros Makarigakis (UNESCO), Toshimitsu Komatsu (WFEO), Satoru Nishikawa (Water Agency, Japan), Badaoui Rouhban (IPL-ICL), Paolo Canuti (ICL), Yueping Yin (ICL), Matjaz Mikos (ICL). Left bottom Qunli Han (UNESCO) and Franco Gabrielli (Italian Civil Protection)

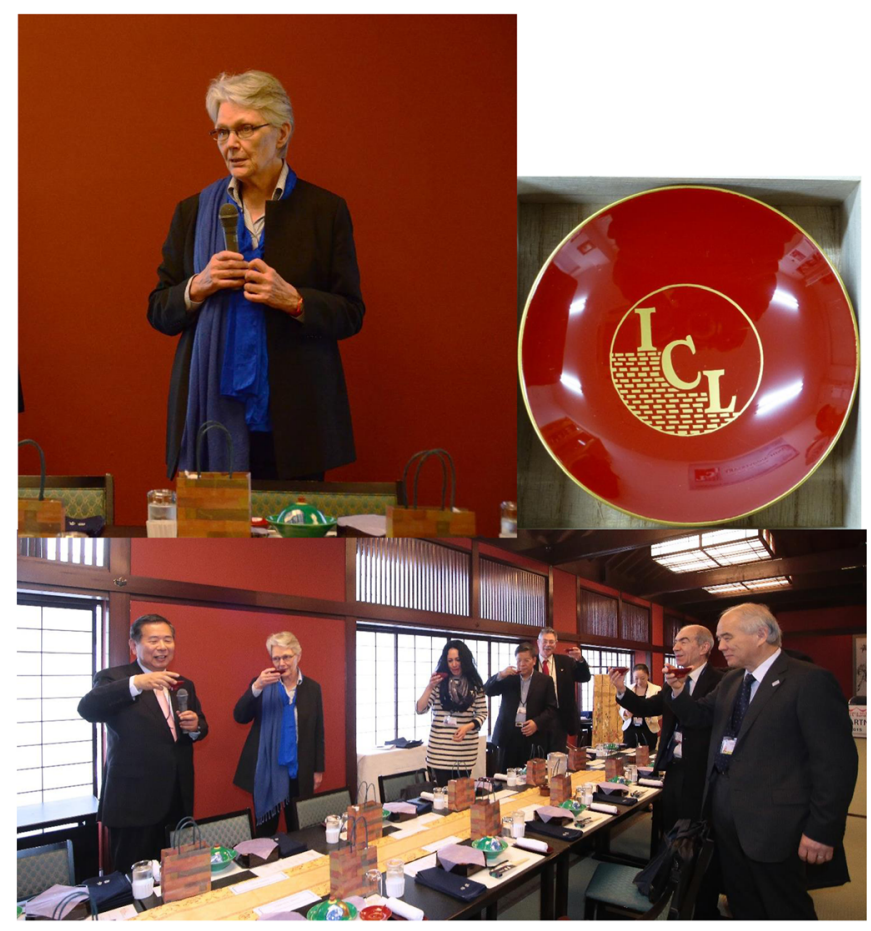

Fig. 2 Speech and toast with sake cup designed for Sendai Partnerships. Left-top Speech by Ms. Margareta Wahlström celebrating the launch of the ISDR-ICL Sendai Partnerships 2015-2025. Right-top Originally designed sake cup for the cerebration of the Sendai Partnerships. Bottom Thanks for all partners by Mr. Kyoji Sassa and toast for the success of the the ISDR-ICL Sendai Partnerships 2015 
Japan Science and Technology Agency (JST). Participants reviewed the first decade of ICL and IPL activities and examined the second decade of ICL-IPL activities. As a result, ICL Strategic Plan 2012-2021-To create a safer geoenvironment was adopted (Sassa 2012). This conference approved the establishment of four regional networks and five thematic networks of ICL to expand the activities of ICL members and cooperation with non-ICL members in the specific region and themes. ICL organized the ICL-IPL Conference in Kyoto, Japan, in 2013 with financial supports from JST. At this conference, ICL discussed and made the 20014 Beijing Declaration to be adopted in the World Landslide Forum 3 in Beijing, China on 2-6 June 2014. Furthermore, ICL examined and made the draft of ICL-IPL Sendai Partnerships 20152025-Landslide disaster risk reduction for a safer geoenvironment to be examined in Sendai, Japan, in
March 2015. The 2004 Beijing Declaration-Landslide Mitigation Toward a Safer Geoenvironment was examined in the high-level panel discussion with the participation of the Director-General of UNESCO Ms. Irina Bokova and was adopted at the end of $\mathrm{WLF}_{3}$ in Beijing, China, that was held on 2-6 June 2014.

ICL organized the Steering Committee meeting in Kyoto on 7-9 October 2014 together with the International Forum "Urbanization and Landslide Disaster"-Hiroshima landslide disaster in August, 2014 and Japan's contribution to Post-2015 Framework for Disaster Risk Reduction. This forum, together with ICL Steering Committee meeting, was planned as a preparatory meeting of the ICL-IPL Sendai Partnerships Conference on 11-15 March 2015. Key members of ICL, UNESCO, UNISDR, Ministry of Education, Culture, Sports, Science and Technology, Government of Japan (MEXT), and

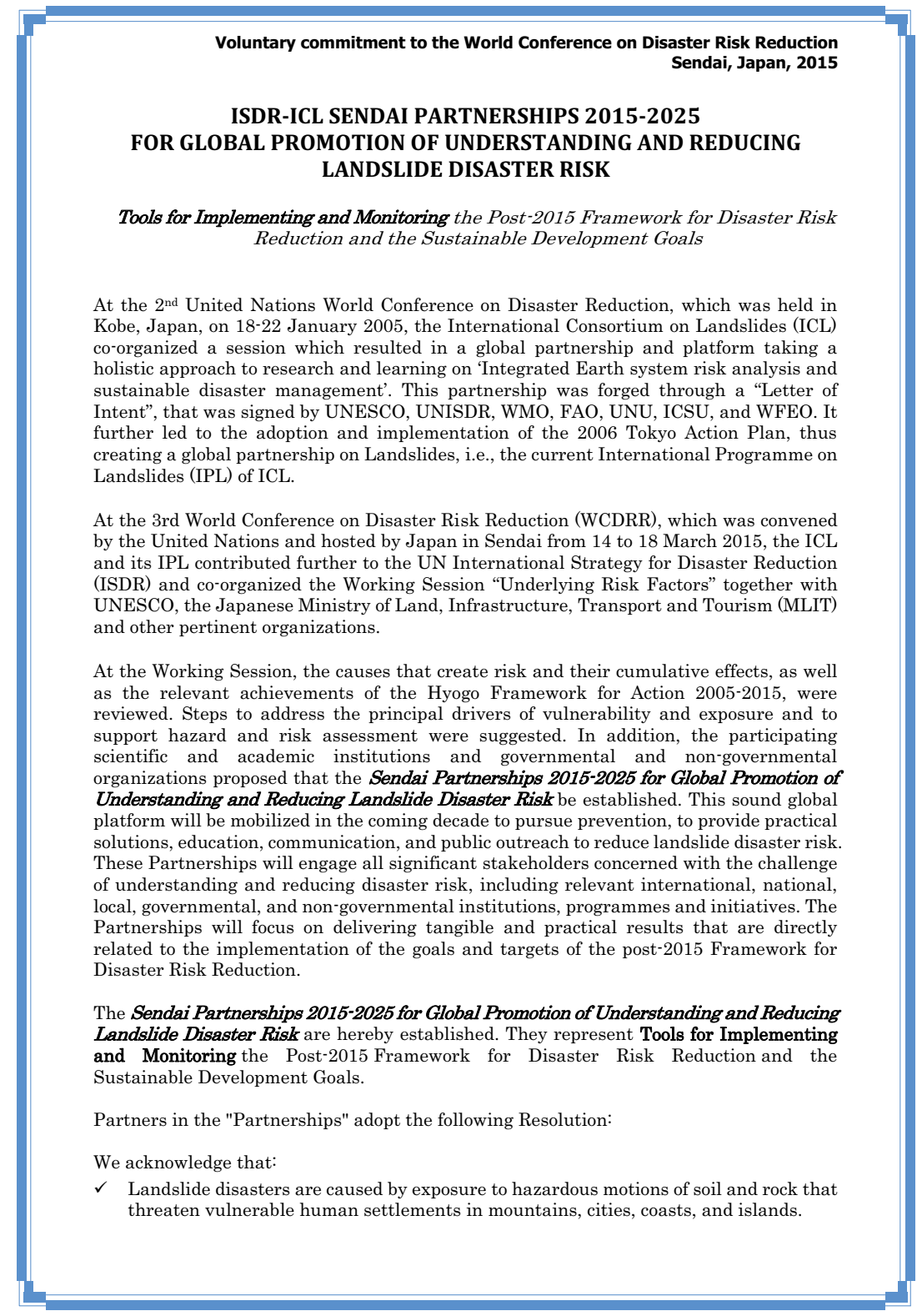

Fig. 3 ISDR-ICL SENDAI PARTNERSHIPS 2015-2025 for global promotion of understanding and reducing landslide disaster risk 


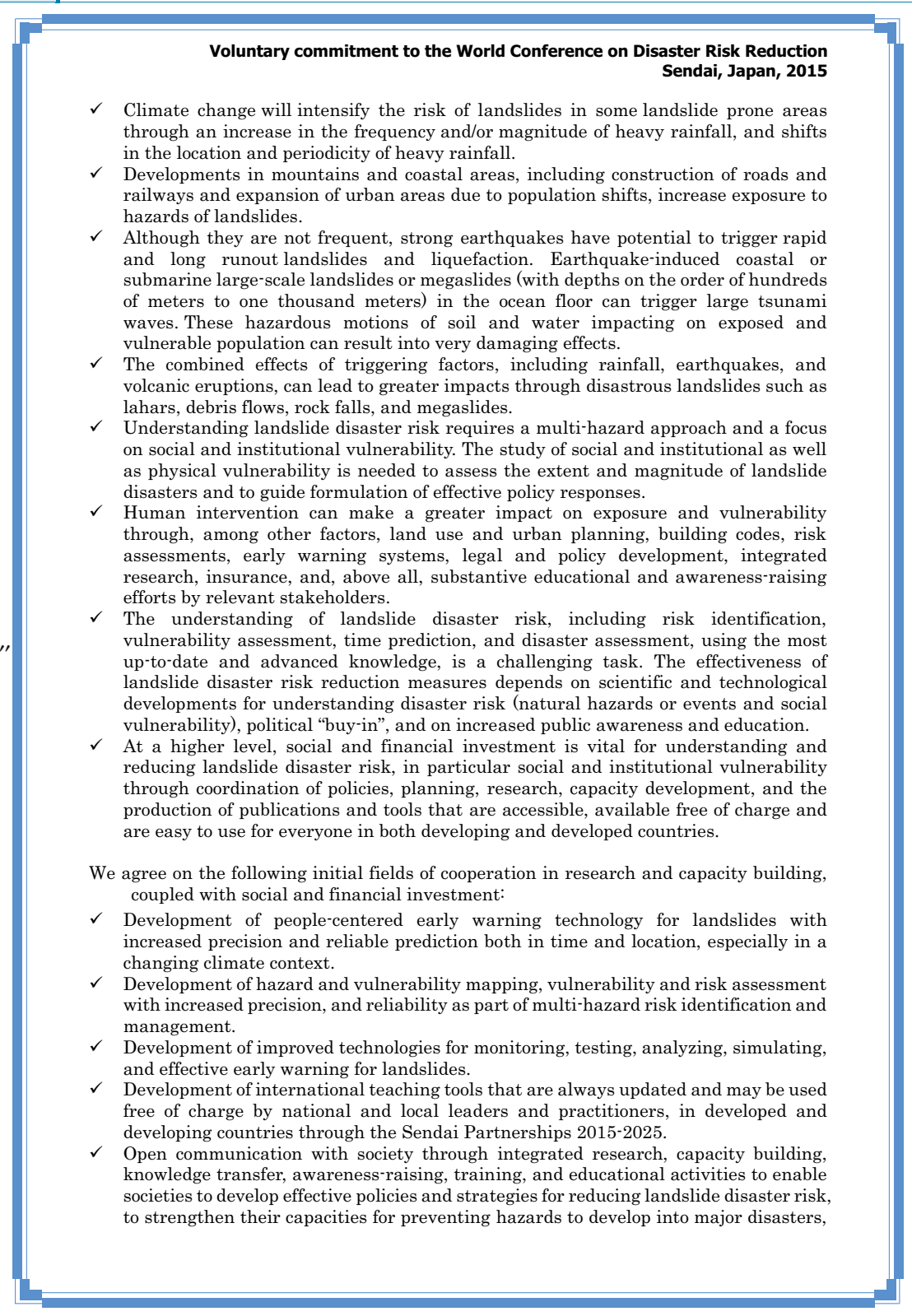

Fig. 3 (continued)

the Cabinet Office and the Ministry of Land, Infrastructure, Transport, and Tourism (MLIT), Government of Japan attended and discussed for the global collaborative framework contributing to the Third World Conference on Disaster Risk Reduction.

\section{Establishment of the ISDR-ICL Sendai Partnerships 2015-2025}

ICL initially proposed a thematic session "Urbanization and Geodisasters" to be considered as part of the Third WCDRR. This topic was not retained among the topics of the conference. Thereafter, ICL succeeded to be a co-organizer of the Working Session No. 4 (WS 4) "Underlying Risk Factors" (Priority No. 4 of the Hyogo Framework for Action) together with MLIT, UNESCO, and other organizations under the initiative of ISDR. ICL proposed a Sendai Partnership on
Landslides to the session. It was changed from the initial proposal of "ICL-IPL Sendai Partnerships 20152024-Landslide disaster risk reduction for a safer geoenvironment" to the Sendai Partnerships for the Global Promotion of Understanding Disaster Risk (Priority 1 of the Sendai Framework for Disaster Risk Reduction 2015-2030) so as to widen the scope beyond only landslides. However, an opinion came that it is too wide, the session should focus specific disasters within the interest of organizers of the Working Session No. 4. Then, it was changed to the ISDRICL: SENDAI PARTNERSHIPS 2015-2024 for Global Promotion of Understanding and Reducing Landslide, Flood, and Tsunami Disaster Risk-Tools for Implementing and Monitoring the Post-2015 Framework for Disaster Risk Reduction and the Sustainable Development Goals. This 


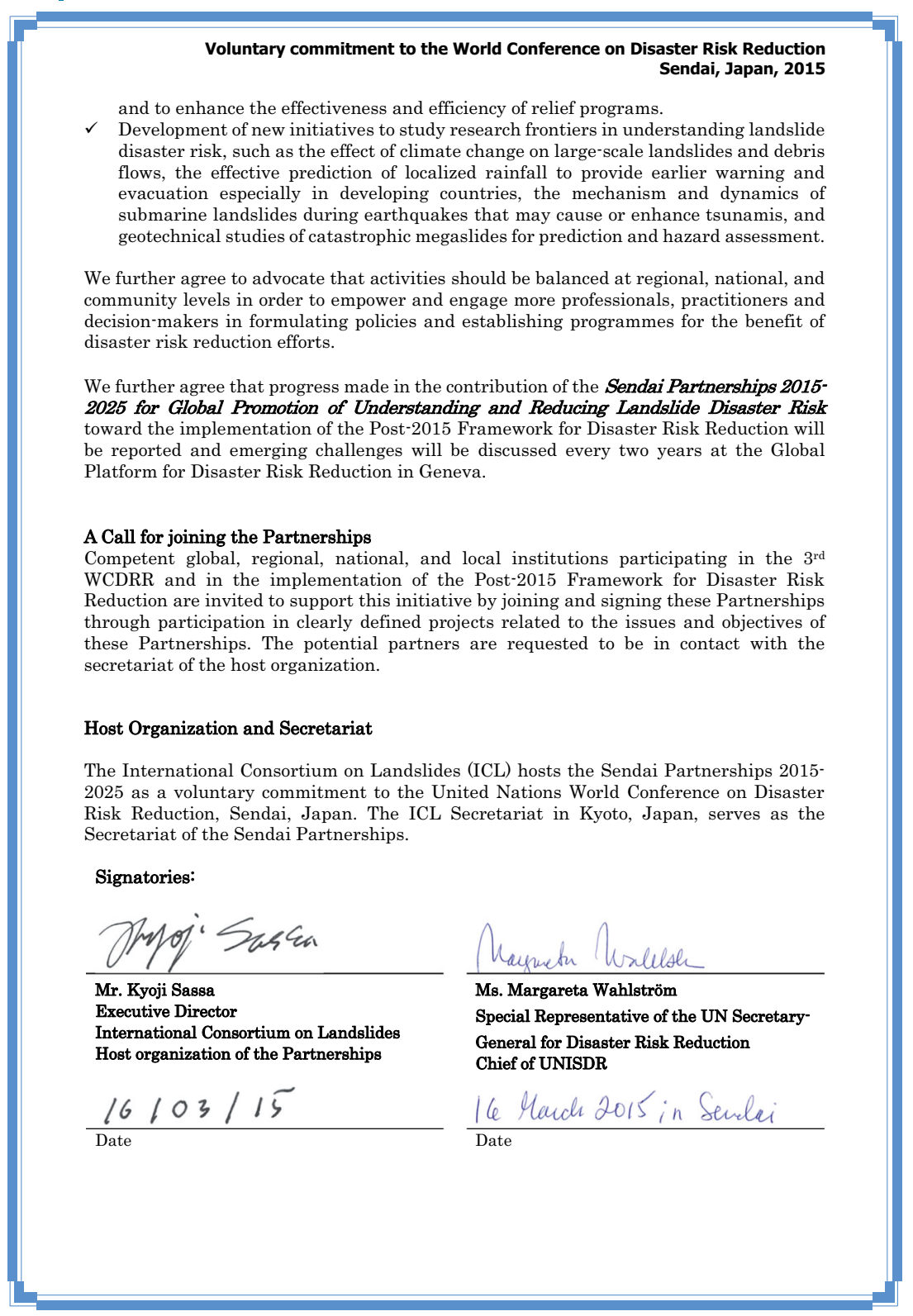

Fig. 3 (continued)

version was circulated to the expected intergovernmental, international, and national organizations on 21 January 2015. However, an opinion suggested that because this partnerships is under the initiative of the International Consortium on Landslides, it is better to focus on landslides. As a result, it was finally returned to only landslides.

The revised title of the finally agreed Sendai Partnerships were

Header: Voluntary commitment to the World Conference on Disaster Risk Reduction, Sendai, Japan, 2015

Title: ISDR-ICL Sendai Partnerships 2015-2025 for global promotion of understanding and reducing landslide disaster risk Subtitle: Tools for Implementing and Monitoring the Post-2015 Framework for Disaster Risk Reduction and the Sustainable Development Goals
This version was sent to intergovernmental and international organizations on 14 February 2015. Based on the various input from those organizations, the main text was further revised. Then, the latest version of partnerships was reported, and its implementation plan was examined in the ICL-IPL Sendai Partnership Conference on 11-15 March 2015. Then, this Sendai Partnerships was proposed to the Working Session No. 4 "Underlying Risk Factors" held at 10:00-11:30 AM in Hagi Hall of the Sendai International Center on 16 March 2015. The chairperson of the session was Mr. Kamal Kishore and the moderator was Mr. Badaoui Rouhban. Dr. Kyoji Sassa proposed this Sendai Partnerships in the final part of the session which was devoted to make statements of commitments on addressing the Underlying Risk Factors in the post-2015 


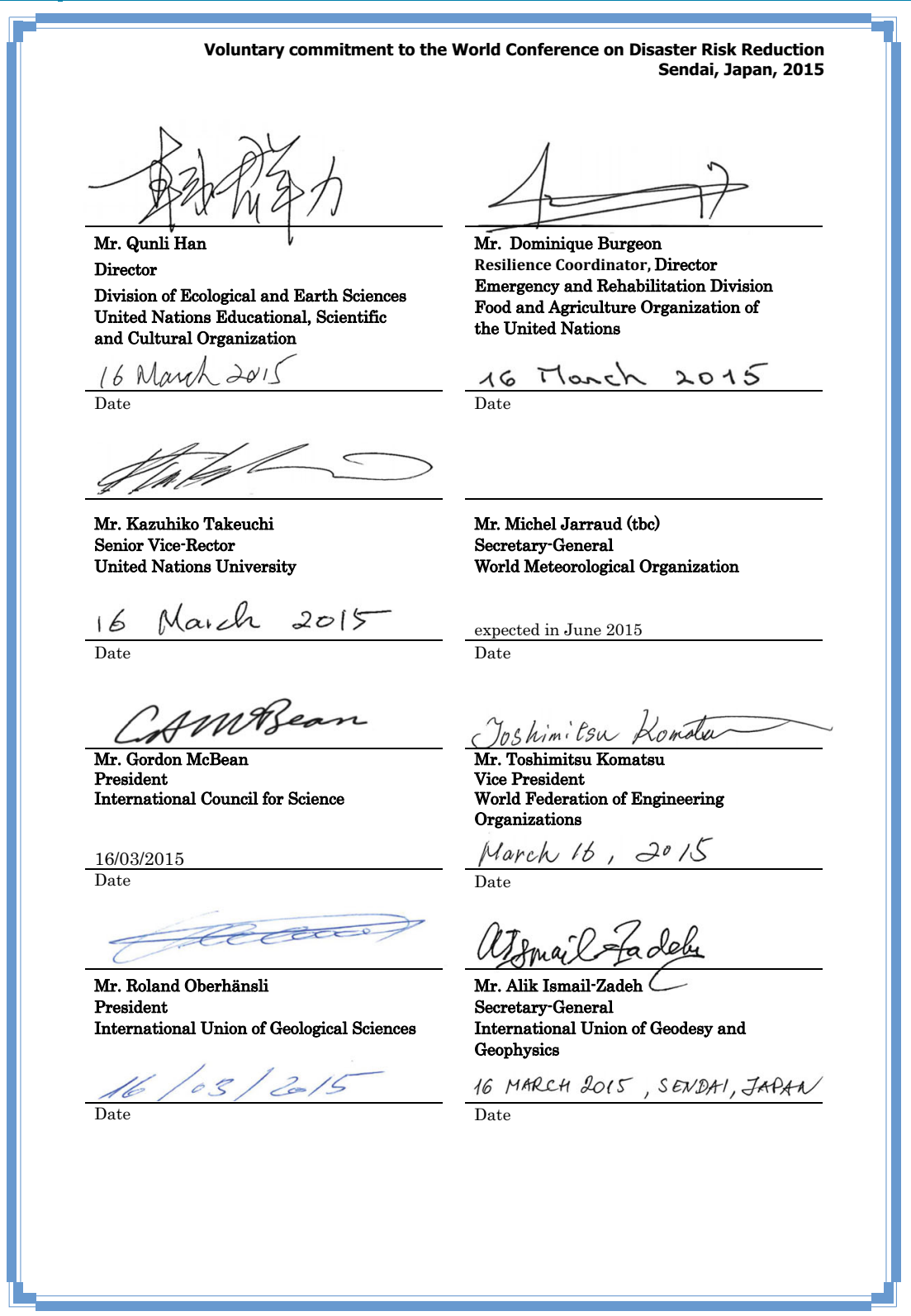

Fig. 3 (continued)

framework for disaster risk reduction. As a result, the launch of the Sendai Partnerships was announced in the session.

Signing ceremony and the Sendai Partnerships

The signing ceremony of the ISDR-ICL Sendai Partnerships was organized in a Japanese Restaurant "JUNSEN" in Sendai, Japan, from 12:00-13:30 on 16 March 2015. Sixteen intergovernmental, international, and national organizations signed the Sendai Partnerships. Heads of some organizations attended and signed there; some organizations nominated an officer in-charge of disaster reduction to sign the documents while some organizations signed it in advance and sent a representative to bring the signed partnerships to this signing ceremony. Following are the organizations which agreed and signed the Sendai Partnerships on 16 March 2015.

1. International Consortium on Landslides (ICL)

2. United Nations Office for Disaster Risk Reduction (UNISDR)

3. United Nations Educational, Scientific and Cultural Organization (UNESCO)

4. Food and Agriculture Organization of the United Nations (FAO)

5. United Nations University (UNU)

6. International Council for Science (ICSU)

7. World Federation of Engineering Organizations (WFEO)

8. International Union of Geological Sciences (IUGS)

9. International Union of Geodesy and Geophysics (IUGG)

10. Cabinet Office, Government of Japan (CAO) 


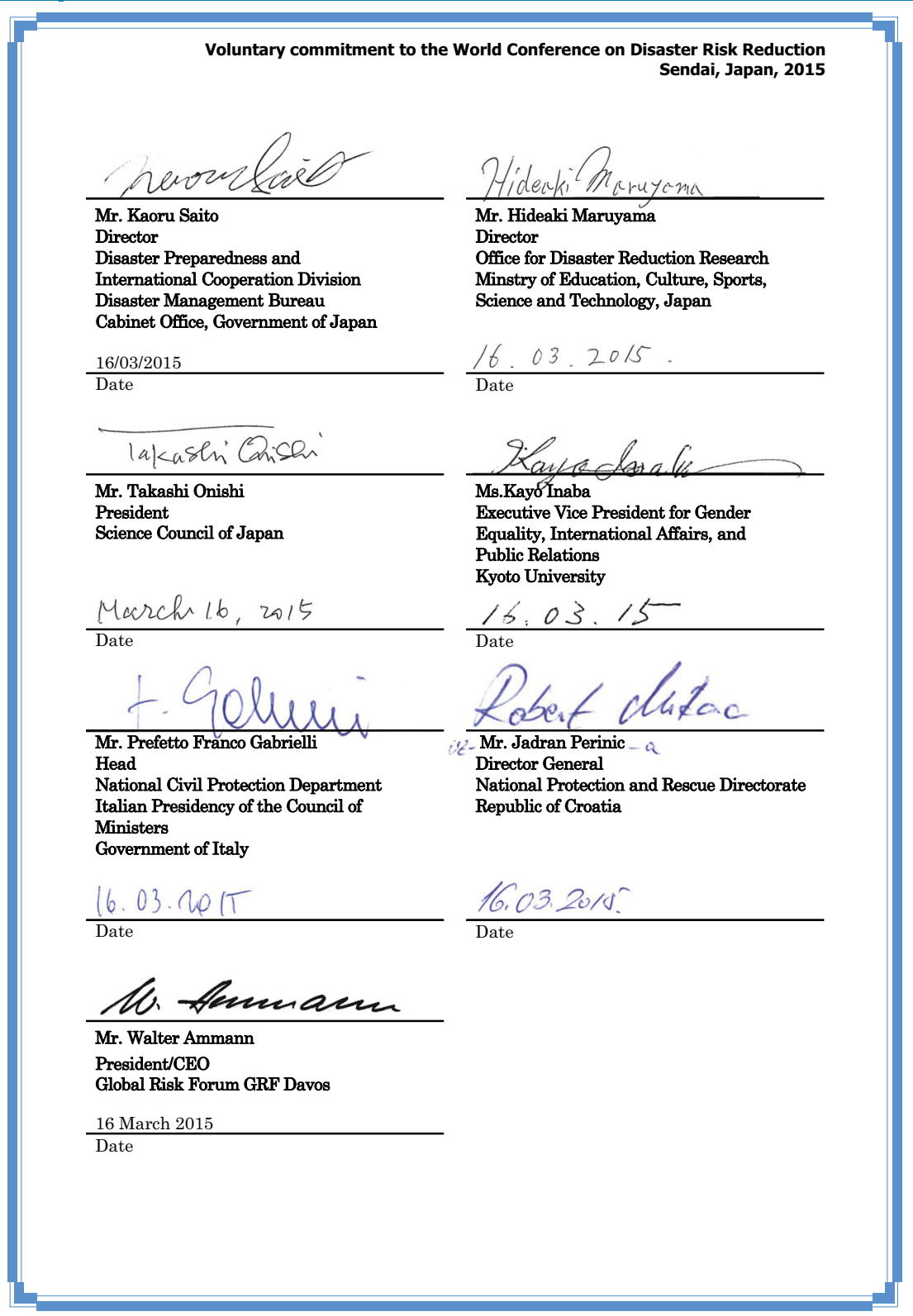

Fig. 3 (continued)

11. Ministry of Education, Culture, Sports, Science and Technology, Government of Japan (MEXT)

12. Kyoto University

13. Science Council of Japan

14. National Civil Protection Department, Italian Presidency of the Council of Ministers, Government of Italy

15. National Protection and Rescue Directorate, Republic of Croatia

16. Global Risk Forum (GRF) Davos

(The WMO is expected to sign after 17 th WMO Congress in May/June 2015).

ICL expects that the ISDR-ICL Sendai Partnerships agreed by the above 16 organizations is a global platform to promote understanding and reducing landslide disaster risk. Social necessity for research and technological development of landslide disaster risk reduction are increasing in the progress of urbanization and the mountain and coastal development especially in changing climate context. ICL wishes to cooperate with many of the involved organizations to reduce landslide disasters in the coming decade.

Figure 1 is a photo of Signing Ceremony; Fig. 2 shows Ms. Margareta Wahlström (left-top) speaking at the ceremony and the toast by Kyoji Sassa (left-bottom) and the SAKE cup designed for the toast in the celebration of the Sendai Partnerships. The cup was made by one of the best Japanese Lacquerware shop in Aizu of Fukushima Prefecture in Japan. The sake cup is made from a wooden cup, URUSHI lacquer, and real gold ICL logo. At first, the stamp of ICL logo was created. Stamp with liquid taken from the Japanese URUSHI tree (Toxicodendron vernicifluum, formerly Rhus verniciflua) was pressed on the sake cup. It has strong adhesive force. The cup was covered by full of real gold foils. When all excess foils were removed, the ICL logo and the gold 
Fig. 3 (continued)

edge appeared. The URUSHI is very strong and can stand for a long time. The logo was designed by Sassa at the time of ICL foundation. The ICL investigated the Inca's World Heritage Machu Picchu at landslide risk in those years. I on the top of slope symbolizes human assets at landslide risk (such as Machu Picchu). L symbolizes the landslide disaster risk reduction efforts by humans (such as a retaining wall or a structure to stop moving landslide debris. C symbolizes the consortium as well as landslide mass under rapid motion. Please notice that $\mathrm{C}$ is slightly inclined showing the motion. One opinion from ICL group was that the consortium seems to be not stable and may fall down in this case. It should stand straight. Two opinions are reflected from the background of sciences and technologies of ICL, and both supports were divided into half and half in this cross-disciplinary group. But finally, ICL chose mobility than stability in its logo.
Participants from 16 different types and disciplinary groups toasted for the further progress of landslide disaster risk reduction for the sustainable development in the changing climate context.

The full text of Sendai Partnerships is shown after Figs. 1 and 2. The partnerships include the list of ICL members as of 1 April 2015 as ANNEX. The ANNEX is periodically updated (Fig. 3).

\section{Call for cooperation and acknowledgment}

The Sendai Partnerships is not a declaration but a voluntary commitment to the Third WCDRR. ICL members will intensify its activities for understanding and reducing landslide disaster risk over the world. Four regional and five thematic networks of ICL (Sassa 2012) and 15 World Centres of Excellence on Landslide Risk Reduction (Sassa et al. 2015) as well as 62 member organizations from 33 countries, and 41 IPL project group will contribute to this 
31. University of Tokyo, Geotechnical Engineering Group, JAPAN

32. Niigata University, Research Institute for Natural Hazards and Disaster Recovery, JAPAN

33. Forestry and Forest Product Research Institute, JAPAN

34. Japan Landslide Society, JAPAN

35. Korea Institute of Geoscience and Mineral Resources (KIGAM), REPUBLIC OF KOREA

36. Korea Forest Research Institute, REPUBLIC OF KOREA

37. Korea Infrastructure Safety \& Technology Corporation, REPUBLIC OF KOREA

38. Korea Institute of Construction Technology, REPUBLIC OF KOREA

39. Korean Society of Forest Engineering, REPUBLIC OF KOREA

40. Slope Engineering Branch, Public Works Department of Malaysia, MALAYSIA

41. Institute of Geography, UNAM, MEXICO

42. International Centre for Integrated Mountain Development (ICIMOD), NEPAL

43. Department of Geology, University of Nigeria, Nsukka, NIGERIA

44. Norwegian Geotechnical Institute (NGI), Oslo, NORWAY

45. Grudec Ayar, PERU

46. Department of Engineering and Ecological Geology, Moscow State University, RUSSIA

47. JSC "Hydroproject Institute", RUSSIA

48. Russian Academy of Sciences, Sergeev Institute of Environmental Geoscience (IEG RAS), RUSSIA

49. University of Belgrade, Faculty of Mining and Geology, SERBIA

50. Comenius University, Faculty of Natural Sciences, Department of Engineering Geology, SLOVAKIA

51. University of Ljubljana, Faculty of Civil and Geodetic Engineering (ULFGG), SLOVENIA

52. Geological Survey of Slovenia, SLOVENIA

53. Central Engineering Consultancy Bureau (CECB), SRI LANKA

54. National Building Research Organization, SRI LANKA

55. Landslide group in National Central University from Graduate Institute of Applied Geology, Department of Civil Engineering, Center for Environmental Studies, CHINESE TAIPEI

56. National Taiwan University, Department of Civil Engineering, CHINESE TAIPEI

57. Ministry of Agriculture and Cooperatives, Land Development Department, THAILAND

58. Asian Disaster Preparedness Center, THAILAND

59. Institute of Telecommunication and Global Information Space, UKRAINE

60. California State University, Fullerton, USA \& Tribhuvan University, Institute of Engineering, Nepal, USA/NEPAL

61. Institute of Transport Science and Technology, Ministry of Transport, VIET NAM

62. Vietnam Institute of Geosciences and Mineral Resources,Ministry of Natural Resources and Environment, VIET NAM

Fig. 3 (continued)

Sendai Partnerships with supports from 15 intergovernmental, international, and national organizations in their countries or regions. ICL wishes to obtain supports from national and local governments, funding agencies, and also non-ICL scientists, engineers, and private sectors for this partnerships.

One of the core activities of this partnerships is to create ISDRICL Landslide Teaching Tools. We discussed this on 15 March 2015 in Sendai, Japan. We will make efforts to create the first version of this Teaching Tools and examine it in the next ICL-IPL meeting as the follow-up and implementing meeting of the Sendai Partnerships. The meeting will be organized in Kyoto, Japan, on 8-11 March 2016. Participations from the 16 partners, new partners, and experts on landslides are requested to attend and cooperate with this voluntary commitment to the Third WCDRR. No registration fee is required.
The JST and the UNESCO financially supported this series of meetings in 2012, 2013, and 2015. The IUGS is appreciated for providing financial support annually to the ICL activities. Many colleagues supported the establishment of this Sendai Partnerships. Those individuals can be seen in the photo of Fig. 1. The following individuals are especially appreciated for the establishment of Sendai Partnerships and signatures.

Ms. Margareta Wahlström, Ms. Feng Min Kan, and Ms. Yuki Matsuoka of the United Nations Office for International Strategy for Disaster Risk Reduction, Mr. Qunli Han and Mr. Giuseppe Arduino, Mr. Alexandros Makarigakis of UNESCO, Mr. Kaoru Saito of the Cabinet Office, Government of Japan, Mr. Satoru Nishikawa of the Water Agency of Japan, Mr. Badaoui Rouhban, IPL advisor, and 
Mr. Hans van Ginkel and Mr. Salvano Briceno who advised the partnerships but could not came to Sendai. Mr. Franco Gabrielli and Mr. Robert Mikac from governments of Italy and Croatia, Mr. Dominique Burgeon (FAO), Mr. Roland Overhansli (IUGS), and Mr. Alik Ismail-Zedeh (IUGG), Mr. Takashi Onishi of Science Council of Japan, Mr. Toshimitsu Komatsu (WFEO) attended and signed the partnerships on the site. Mr. Srikantha Herath for Kazuhiko Takeuchi of UNU, Mr. Kaoru Takara (ICL Treasurer) for Ms. Kayo Inaba of Kyoto University, Ms. Irasema Alcantara-Ayala (ICL vice president) for Gordon Mcbean of ICSU attended together with signed partnerships of those organizations. ICL President Yueping Yin, the past ICL President Paolo Canuti, four Vice presidents, and representatives of 62 ICL member organizations are very much appreciated for their supports and further contribution to this partnerships.

\section{References}

Sassa K (2004a) The International Consortium on Landslides. Landslides 1(1):91-94 Sassa K (2004b) The International Programme on Landslides. Landslides 1(2):95-99 Sassa K (2006) 2006 Tokyo Action Plan-strengthening research and learning on landslides and related earth system disasters for global risk preparedness. Landslides 3(4):361-369 Sassa K (2012) ICL Strategic Plan 2012-2021-to create a safer geoenvironment. Landslides 9(2):155-194

Sassa K, Yin Y, Canuti P (2015) The Third World Landslide Forum, Beijing, 2014. Landslides 12(1):177-192

K. Sassa (-a)

International Consortium on Landslides (ICL),

Kyoto, Japan

e-mail: sassa@iclhq.org 